\title{
Reactive hyperemia index (RHI) and cognitive performance indexes are associated with histologic markers of liver disease in subjects with non-alcoholic fatty liver disease (NAFLD): a case control study
}

Antonino Tuttolomondo ${ }^{1 *}$, Salvatore Petta², Alessandra Casuccio ${ }^{3}$, Carlo Maida ${ }^{1}$, Vittoriano Della Corte ${ }^{1}$,

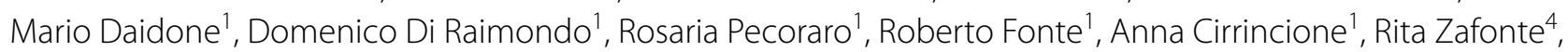
Daniela Cabibi ${ }^{5}$, Calogero Cammà ${ }^{2}$, Vito Di Marco², Anna Licata ${ }^{2}$, Franco Magliozzo ${ }^{4}$, Giulio Marchesini ${ }^{6}$, Giovanni Merlino ${ }^{4}$, Antonio Craxi $^{2}$ and Antonio Pinto ${ }^{1}$

\begin{abstract}
Background: No study evaluated vascular health markers in subjects with non-alcoholic fatty liver disease (NAFLD) through a combined analysis of reactive hyperemia peripheral arterial tonometry (RH-PAT) and arterial stiffness indexes.
\end{abstract}

Aim of the study: We aimed to assess whether NAFLD and its histological severity are associated with impairment of arterial stiffness and RH-PAT indexes in a mixed cohort of patients with biopsy-proven NAFLD.

Materials and methods: The Kleiner classification was used to grade NAFLD grade. Pulse wave velocity (PWV) and augmentation index (Aix) were used as markers of arterial stiffness, whereas endothelial function was assessed using reactive hyperemia index $(\mathrm{RHI})$. The mini-mental state examination (MMSE) was administered to test cognitive performance.

Results: 80 consecutive patients with biopsy-proven NAFLD and 83 controls without fatty liver disease. NAFLD subjects showed significantly lower mean RHI, higher mean arterial stiffness indexes and lower mean MMSE score. Multivariable analysis after correction for BMI, dyslipidaemia, hypertension, sex, diabetes, age and cardiovascular disease showed that BMI, diastolic blood pressure and RHI are significantly associated to NAFLD. Simple linear regression analysis showed among non-alcoholic steatohepatitis (NASH) subjects a significant negative relationship between ballooning grade and MMSE and a significant positive association between Kleiner steatosis grade and augmentation index.

Conclusions: Future research will be addressed to evaluate the relationship between inflammatory markers and arterial stiffness and endothelial function indexes in NAFLD subjects. These study will evaluate association between cardiovascular event incidence and arterial stiffness, endothelial and cognitive markers, and they will address the beneficial effects of cardiovascular drugs such as statins and ACE inhibitors on these surrogate markers in NAFLD subjects. Keywords: Non-alcoholic fatty liver disease, Histopathology, Liver fibrosis

\footnotetext{
*Correspondence: bruno.tuttolomondo@unipa.it

${ }^{1}$ U.O.C di Medicina Interna con Stroke Care, Dipartimento Biomedico di Medicina Interna e Specialistica (Di.Bi.M.I.S), University of Palermo, P.zza delle Cliniche n.2, Palermo 90127, Italy

Full list of author information is available at the end of the article
} 


\section{Introduction}

Liver is a target organ in metabolic syndrome (MS) patients in which it manifests itself with non-alcoholic fatty liver disease (NAFLD) spanning steatosis via steatohepatitis and cirrhosis (1.2). Non-alcoholic fatty liver disease and non-alcoholic steatohepatitis (NASH) have been reported as associated with cardiovascular events [1-3].

Several useful surrogates in the clinical setting include Framingham Risk Score, carotid artery intima-media thickness, high sensitivity C-reactive protein (hsCRP), visceral and mediastinal fat, and coronary calcium scores $[4,5]$.

Forearm flow-mediated vasodilation (FMD) is a commonly used method for the assessment of endothelial dysfunction [6]. However, findings offered by FMD can be very different owing to technical issues thus this method has been reported as not standardized [7].

Reactive hyperemia peripheral arterial tonometry ( $\mathrm{RH}-$ PAT) is a new method useful to measure endothelial dysfunction that has been reported by Kuvin et al. [8]. This method is noninvasive, and quantitative and it offers a digital measurement of hyperemic response. Framingham Heart Study reported that reactive hyperemia index (RHI) is inversely correlated with various cardiovascular risk factors [9].

Adjunctive surrogates for cardiovascular risk more recently validated by some studies $[10,11]$ are arterial stiffness and endothelial function indexes.

Augmentation pressure and pulse wave velocity (PWV) have been reported as surrogate markers for cardiovascular disease [10]. They are both two markers of endothelial dysfunction and vascular damage [11] and some studies analyzed arterial stiffness indexes in NAFLD patients [12-14].

Vlachopoulos et al. [12] reported that NAFLD subjects showed significantly higher carotid-femoral pulse wave velocity and reduced flow-mediated dilatation (FMD) and that at multivariable analysis, presence of NAFLD was an independent determinant of both PWV and FMD. In another study Salvi et al. [13] reported that patients with NAFLD and MS PWV values were significantly higher in comparison to controls and to NAFLD subjects without MS.

Nonetheless, only a study [15] analyzed endothelial dysfunction in these subjects using flow mediated dilation and flow-mediated vasoactivity (FMV) findings. Authors reported that NAFLD was associated with a percent FMV in the lower tertile after adjustment for age, sex, body mass index, and insulin resistance and that among NAFLD patients, low FMV was associated with nonalcoholic steatohepatitis.

Vascular disease seems to be important in cognitive impairment and cerebrovascular disease, including white matter lesions and silent infarcts that may lead to a specific pattern of cognitive impairment. It explains that cognitive function indexes such as mini-mental state examination (MMSE) scores could be putative to be considered a surrogate vascular marker.

Thus, the evaluation by means the analysis of RH-PAT indexes, arterial stiffness markers and cognitive performance could offer a more complete and useful information with regard of the vascular health status of NAFLD patients.

No study, to the best of our knowledge, has analyzed endothelial dysfunction in subjects with NAFLD through an analysis of RH-PAT indexes. Furthermore no study analyzed the relationship between histological severity of NAFLD and arterial stiffness and RH-PAT indexes and no study evaluated cognitive indexes as surrogate vascular markers in association with other surrogate markers such as arterial stiffness and endothelial function indexes, whereas only one study evaluated the relationship between cognitive function and NAFLD [14].

Considering the link between NAFLD, its related metabolic changes and cardiovascular risk, to assess whether NAFLD and its histological severity is related to the impairment of some surrogate markers of vascular impairment, we designed a study with a principal aim:

1. To evaluate arterial stiffness and RH-PAT indexes in a mixed cohort of patients with biopsy-proven NAFLD in comparison with subjects without fatty liver and with regard to NASH presence; and two secondary aims:

2. To evaluate cognitive performance measured by MMSE in a mixed cohort of patients with biopsyproven NAFLD in comparison with subjects without fatty liver and with regard to NASH presence;

3. To analyze the relationship between hepatic histological findings of NAFLD and surrogate markers of vascular impairment (arterial stiffness and RH-PAT indexes and cognitive performance index).

\section{Patients and methods \\ Patients}

We recruited all NAFLD patients admitted to the Gastrointestinal \& Liver Unit of Palermo University Hospital from June 2014 to December 2015.

Inclusion criteria were: (1) a histological diagnosis of NAFLD on a liver biopsy obtained less than 6 months before enrollment.

A pre-biopsy evaluation of NAFLD was based on these findings: increased serum levels of alanine transaminase (ALT) for at least 6 months and alcohol consumption of $<20 \mathrm{~g}$ /day in the previous year (also confirmed by a questionnaire). Liver ultrasound was performed in all 
groups (study group and control) and patients were also recruited by ultrasound (US) finding of steatosis, and a liver stiffness value $>6 \mathrm{kPa}$.

Exclusion criteria were: (1) steatosis, (2) decompensated cirrhosis; (3) hepatocellular carcinoma; (4) liver disease of different or mixed etiology (alcoholic, viral, autoimmune Wilson's disease, hemochromatosis, $\alpha 1$-antitrypsin deficiency); (5) human immunodeficiency virus infection; [6] regular use of steatosis-inducing drugs (steroid, amiodarone, tamoxifen, etc.).

Subjects without NAFLD were referred from general practitioners or they were recruited among patients admitted to Internal Medicine and Stroke Care ward of Policlinico Universitario "P. Giaccone", University of Palermo, Italy. All the subjects enrolled as controls had no history of previous cardiovascular or cerebrovascular disease or metabolic disease or acute disease such as acute myocardial infarction (AMI) or stroke or infections or deep venous thrombosis. They were metabolic and cardiovascular disease free subjects referred from general practioners or admitted to our department for another disease else those indicated as exclusion criteria in the same period.

Among 209 that were evaluated, 120 had no steatosis but satisfied all the criteria indicated above. They had no previous history of previous cardiovascular events, no history of liver disease, no evidence of viral infection (anti-HCV, anti-HIV, and HBsAg negativity), alcohol consumption $>20 \mathrm{~g} /$ day during the previous year (evaluated by a specific questionnaire), normal alanine transaminase values $(<37 \mathrm{UI} / \mathrm{l})$, no ultrasound (US) finding of steatosis, and a liver stiffness value $<6 \mathrm{kPa}$.

\section{Consent for publication}

All enrolled patients released a consent to publish from the participant (or legal parent or guardian for children) to report individual patient data.

\section{Availability of data and material}

All data and material are available on figshare.

\section{Clinical and laboratory assessment}

Clinical and anthropometric data were collected at the time of enrollment. Subjects were classified as normal weight (BMI 18.5-24.9 $\mathrm{kg} / \mathrm{m}^{2}$ ), overweight (BMI 25-29.9), obese (BMI $\geq 30$ ). The diagnosis of arterial hypertension was based on the following criteria: systolic blood pressure $\geq 140 \mathrm{mmHg}$ and/or diastolic blood pressure $\geq 90 \mathrm{mmHg}$ (measured three times within $30 \mathrm{~min}$, in the sitting position and using a brachial sphygmomanometer), or use of blood-pressure-lowering agents [16]. The diagnosis of type 2 diabetes was based on the revised criteria of the American Diabetes Association, using a value of fasting blood glucose $\geq 126 \mathrm{mg} / \mathrm{dl}$ [17]. In patients with a previous diagnosis of type 2 diabetes, current therapy with insulin or oral hypoglycemic agents was documented. A 12-h overnight fasting blood sample was drawn at the time of enrollment to determine the serum levels of ALT, total cholesterol, HDL-cholesterol, triglycerides, plasma glucose, insulin (for NAFLD only), and platelet count (for NAFLD). Dyslipidemia was defined as Triglyceride (TG) level $\geq 150 \mathrm{mg} / \mathrm{dl}$ and total cholesterol levels $>200 \mathrm{mg} / \mathrm{dl}$. We also performed HDL-levels categorization according to a gender-specific threshold for HDL (40 mg/dl for male and $50 \mathrm{mg} / \mathrm{dl}$ for females) [18].

\section{Ultrasound assessment}

Ultrasound assessment was performed on fasting subjects, on the day of liver biopsy for NAFLD, and on the day of enrollment of the controls, by one operator trained in ultrasound techniques and dedicated to liver examination. A real-time Hitachi $\mathrm{H} 21$ apparatus with a $2-5 \mathrm{MHz}$, convex, multi-frequency probe was used. Presence of hepatic steatosis was defined by detection of Bright Liver Echo pattern (BLEP), i.e. fine, packed and high amplitude echoes, with consequent brightness of liver, increase in liver-kidney contrast and possible evidence of vascular blurring and deep attenuation signs [19].

\section{Liver stiffness measurement (LSM)}

Transient elastography was performed with the FibroScan (Echosens, Paris, France) medical device, using the $\mathrm{M}$ probe (also called standard probe), following the ultrasound examination, by trained operators who had previously performed at least 300 determinations in patients with chronic liver disease. As recently reported in the literature [20], we classified LSM examinations into three reliability categories: "very reliable" $(\mathrm{IQR} / \mathrm{M} \leq 0.10)$, "reliable" $(0.10<\mathrm{IQR} / \mathrm{M} \leq 0.30$, or $\mathrm{IQR} / \mathrm{M}>0.30$ with LSM median < $7.1 \mathrm{kPa}$ ), and "poorly reliable" $(\mathrm{IQR} / \mathrm{M}>0.30$ with $\mathrm{LSM}$ median $\geq 7.1 \mathrm{kPa})$. "Poorly reliable" results were excluded from the analysis.

\section{Assessment of histology}

Slides of NAFLD were coded and read by one pathologist (D.C.), who was unaware of the patients' identity and history. A minimum length of $15 \mathrm{~mm}$ of biopsy specimen or the presence of at least 10 complete portal tracts was required [21]. Steatosis was assessed as the percentage of hepatocytes containing fat droplets (minimum 5\%), and evaluated as a continuous variable. The Kleiner classification [22] was used to grade steatosis, lobular inflammation, and hepatocellular ballooning, and to stage fibrosis from 0 to 4 [23]. NASH was considered to be present when steatosis, ballooning, and lobular inflammation were present. 


\section{Pulse wave velocity (PWV) measurement}

Carotid-femoral PWV was measured in the supine position using an automatic device (SphygmoCor version 7.1) that measured the time delay between the rapid upstroke of the carotid and femoral artery pulse waves. The distance between the 2 arterial points was measured on the surface of the body using a tape measure. PWV was calculated as the distance traveled by the arterial pulse wave (meters) divided by the time delay between the 2 arterial points (seconds), thus expressed as meters per second.

\section{Pulse wave analysis}

Applanation tonometry was used to record radial artery pressure waveform continuously, and mean values of $\geq 2$ screens of pulse waves of good quality were used for analysis. From the collected data, an averaged radial pressure waveform was generated and a corresponding aortic pressure waveform and BP was calculated by the validated transfer function (SphygmoCor version 7.1). The aortic pressure waveform was used to calculate the AIx (difference in height between the first and second systolic peaks expressed as a percentage of PP).

\section{RH-PAT}

The principle of RH-PAT has been described previously by some researchers [15]. Briefly, blood pressure cuff was placed on 1 upper arm, while the contralateral arm served as a control. PAT probes were placed on 1 finger of each hand. After a 5 min equilibration period, the cuff was inflated to $60 \mathrm{mmHg}$ above the systolic pressure or $200 \mathrm{mmHg}$ for $5 \mathrm{~min}$ and then deflated to induce reactive hyperemia.

The RH-PAT data were digitally analyzed online (EndoPAT2000 software version 3.0.4). The RH-PAT index reflects the extent of reactive hyperemia and was calculated as the ratio of the average amplitude of PAT signal over 1 min starting 1.5 min after cuff deflation (control arm, A; occludedarm, C) divided by the average amplitude of PAT signal of a 2.5 min time period before cuff inflation (baseline) (control arm, B; occluded arm, D). Thus RH-PAT index $(\mathrm{RHI})=(\mathrm{C} / \mathrm{D}) /(\mathrm{A} / \mathrm{B}) \times$ baseline correction.

\section{Assessment of cognitive function (mini-mental state examination)}

The mini-mental state examination (MMSE) a tool that can be used to systematically and thoroughly assess cognitive function was administered. It is an 11-question measure that tests 5 areas of cognitive function (orientation, registration, attention and calculation, recall, and language). The maximum score is 30 whereas an MMSE value $<24$ ( 23 or lower) is indicative of cognitive impairment [24].

\section{Statistical analysis}

Statistical analysis of quantitative and qualitative data, including descriptive statistics, was performed for all items. Continuous data are expressed as mean $\pm \mathrm{SD}$, unless otherwise specified. Baseline differences between groups were assessed by the Chi square test or Fisher exact test, as needed for categorical variables, and by the independent Student $t$ test for continuous parameters.

The analysis of variance (ANOVA) was performed for parametric variables in univariable and multivariable model to evaluate the difference between NASH vs no NASH patients. In both models the data were adjusted for BMI, dyslipidaemia, hypertension, sex, diabetes, cardiovascular disease and age.

Simple linear regression analysis was used to assess histological hepatic damage markers (Kleiner classification indexes) independently associated with vascular damage indexes in NASH and no NASH patients, respectively. B coefficients (B) and their 95\% confidence intervals (CIs) were also calculated and adjusted for BMI, dyslipidaemia, hypertension, sex, diabetes, cardiovascular disease and age. In the model, the dependent variables were RHI, PWV, Aix and MMSE. Data were analyzed by the SPSS Software 22.0 version (IBM Corp., Armonk, NY, USA). All p-values were two-sided, and p-values less than 0.05 were considered statistically significant.

\section{Results}

The study involved 80 consecutive patients with biopsyproven NAFLD and 83 controls without a fatty liver disease. General and laboratory variables of patients with NAFLD and controls are listed in Table 1.

NAFLD subjects in comparison to controls had a higher BMI ( $28.7 \pm 5.6$ vs. $25.3 \pm 3.8$; $\mathrm{p}=0.005)$ and liver stiffness $(9.37 \pm 7.7$ vs $4.5 \pm 0.4 \mathrm{kPa})$ and they were more likely to have hypertension ( $35 \%$ vs. $15.7 \%$; $\mathrm{p}=0.006$ ) and diabetes ( $38.8 \%$ vs. $8.4 \%, \mathrm{p}=0.005)$.

NAFLD subjects in comparison to controls also had a significantly lower mean RHI ( $1.85 \pm 0.5$ vs. $2.20 \pm 0.6$; $\mathrm{p}=0.005)$ and higher mean arterial stiffness indexes such as Aix $(144.3 \pm 27.2$ vs. $131.4 \pm 31.4, \mathrm{p}=0.006)$ and PWV $(10.46 \pm 2.1 \mathrm{~m} / \mathrm{s}$ vs. $9.61 \pm 2.30 \mathrm{~m} / \mathrm{s} ; \mathrm{p}=0.015)$. MMSE was available for 139 patients (74 with and 65 without NAFLD), with similar characteristics compared to the entire cohort (data not shown).

NAFLD patients had a lower mean MMSE score $(26.9 \pm 1.6$ vs. $28.0 \pm 1.36 ; p=0.005)$ in comparison with patients without NAFLD.

At univariable analysis we observed a significant relationship between BMI $(p=0.004)$, diastolic blood pressure $(\mathrm{p}=0.019)$, Aix $(\mathrm{p}=0.018)$, MMSE $(\mathrm{p}<0.0001)$, RHI $(\mathrm{p}=0.007)$ and NAFLD, whereas at multivariable analysis after correction for BMI, dyslipidaemia, 
Table 1 Demographic, laboratory and clinical variables in NAFLD subjects and controls

\begin{tabular}{|c|c|c|c|}
\hline Variable & $\begin{array}{l}\text { NAFLD subjects } \\
(\mathrm{n}=80)\end{array}$ & $\begin{array}{l}\text { Controls } \\
(n=83)\end{array}$ & $p$ \\
\hline Age (years) (mean $\pm S D$ ) & $53.7 \pm 12.9$ & $51.7 \pm 17.2$ & 0.401 \\
\hline Weight (kg) (mean \pm SD) & $78.9 \pm 17.7$ & $71.3 \pm 13.4$ & 0.002 \\
\hline $\mathrm{BMI}\left(\mathrm{kg} / \mathrm{m}^{2}\right)($ mean $\pm \mathrm{SD})$ & $28.7 \pm 5.6$ & $25.3 \pm 3.8$ & 0.005 \\
\hline $\mathrm{SBP}(\mathrm{mm} / \mathrm{Hg})($ mean $\pm \mathrm{SD})$ & $121.7 \pm 13.7$ & $122.7 \pm 16.3$ & 0.655 \\
\hline $\mathrm{DBP}(\mathrm{mm} / \mathrm{Hg})($ mean $\pm \mathrm{SD})$ & $72.7 \pm 9.5$ & $75.4 \pm 12.7$ & 0.127 \\
\hline Hypertension (n/\%) & $28(35.0)$ & $13(15.7)$ & 0.006 \\
\hline Diabetes (n/\%) & $31(38.8)$ & $7(8.4)$ & 0.005 \\
\hline Dyslipidaemia (n/\%) & $15(18.8)$ & $14(16.9)$ & 0.839 \\
\hline $\begin{array}{l}\text { Previous cardiovascular } \\
\text { diseases }\end{array}$ & $3(3.75)$ & 0 & 0.341 \\
\hline $\begin{array}{l}\text { Previous cerebrovascular } \\
\text { events }\end{array}$ & 0 & 0 & 0.417 \\
\hline $\mathrm{RHI}($ mean $\pm \mathrm{SD})$ & $1.85 \pm 0.5$ & $2.20 \pm 0.6$ & 0.005 \\
\hline Aix (\%) (mean \pm SD) & $144.3 \pm 27.2$ & $131.4 \pm 31.4$ & 0.006 \\
\hline PWV (mt/s) (mean \pm SD) & $10.46 \pm 2.1$ & $9.61 \pm 2.30$ & 0.015 \\
\hline MMSE (mean \pm SD) & $26.9 \pm 1.6$ & $28.0 \pm 1.4$ & 0.005 \\
\hline Liver stiffness, kPa & $9.37 \pm 7.7$ & $4.5 \pm 0.4$ & 0.005 \\
\hline NASH patients (n/\%) & 52 & & \\
\hline Histology (\%) & $52(65)$ & & \\
\hline \multicolumn{4}{|c|}{ Kleiner steatosis grade 0-3 (mean/SD) } \\
\hline $1(n / \%)$ & $36(45)$ & & \\
\hline $2(n / \%)$ & $22(27.5)$ & & \\
\hline $3(n / \%)$ & $22(27.5)$ & & \\
\hline \multicolumn{4}{|c|}{ Lobular inflammation grade 0-3 (mean/SD) } \\
\hline $0(n / \%)$ & $2(2.5)$ & & \\
\hline $1(n / \%)$ & $45(56.3)$ & & \\
\hline $2(n / \%)$ & $31(38.8)$ & & \\
\hline $3(n / \%)$ & $2(2.5)$ & & \\
\hline \multicolumn{4}{|c|}{ Hepatocellular ballooning 0-2 (mean/SD) } \\
\hline $0(n / \%)$ & $23(28.7)$ & & \\
\hline $1(n / \%)$ & $35(43.8)$ & & \\
\hline $2(n / \%)$ & $22(27.5)$ & & \\
\hline \multicolumn{4}{|c|}{ Stage of fibrosis (0-4) (mean/SD) } \\
\hline $0(n / \%)$ & $18(22.5)$ & & \\
\hline $1(n / \%)$ & $25(31.3)$ & & \\
\hline $2(n / \%)$ & $14(17.5)$ & & \\
\hline $3(n / \%)$ & $17(21.3)$ & & \\
\hline $4(n / \%)$ & $6(7.5)$ & & \\
\hline
\end{tabular}

Liver stiffness: measured by transient elastography (TE) (fibroscan) Significant $\mathrm{p}$ values are indicated in Italics

$S B P$ systolic blood pressure, $D B P$ diastolic blood pressure, $B M I$ body mass index, Aix: augmentation index, $P W V$ pulse wave velocity, $R H I$ reactive hyperemia index, MMSE mini-mental state examination, $k P a$ kilopascal

hypertension, sex, diabetes and age and cardiovascular disease only BMI $(p=0036)$, diastolic blood pressure $(\mathrm{p}=0.048)$, MMSE $(\mathrm{p}<0.0001)$ and RHI $(\mathrm{p}=0.032)$ remained significantly associated to NAFLD (see Table 2).
Table 2 Univariate and multivariate analysis of relationship between clinical variables and NAFLD

\begin{tabular}{lcc}
\hline Dependent variables & F & Sign. \\
\hline Univariable analysis & & \\
Age & 0.011 & 0.915 \\
BMI & 8.452 & 0.004 \\
SBP & 3.854 & 0.051 \\
DBP & 5.581 & 0.019 \\
Aix & 5.751 & 0.018 \\
PWV & 2.223 & 0.138 \\
MMSE & 20.069 & $<0.0001$ \\
RHI & 7.423 & 0.007 \\
Multivariable analysis & & \\
BMI & 4.512 & 0.036 \\
SBP & 3.688 & 0.057 \\
DBP & 3.977 & 0.048 \\
Aix & 1.615 & 0.206 \\
MMSE & 24.999 & $<0.0001$ \\
RHI & 4.722 & 0.032 \\
\hline
\end{tabular}

Adjusted for BMI, dysilipidaemia, hypertension, sex, diabetes and age

Significant $\mathrm{p}$ values are indicated in Italics

In NAFLD subjects we observed no significant difference with regard to vascular damage markers and MMSE score accordingly to NASH presence or absence (see Table 3).

In NAFLD subjects we also observed no significant difference with regard of vascular damage markers an MMSE score accordingly to fibrosis severity (see Table 4).

At simple linear regression, after correction for BMI, dyslipidaemia, hypertension, sex, diabetes, age and cardiovascular disease, analysis of the relationship between hepatic histological findings and vascular damage markers, showed a significant negative relationship linking MMSE and Kleiner ballooning grade [B $=-1.344(95 \%$ $\mathrm{CI}=-2.650$ to 0.037$) ; \mathrm{p}=0.044]$ and a significant positive relationship linking Aix and Kleiner steatosis grade $[\mathrm{B}=4.957$ (95\% $\mathrm{CI}=1.385-8.529) ; \mathrm{p}=0.008]$ in NAFLD subjects with NASH (see Table 5).

No significant relationship was observed between hepatic histological findings and vascular damage markers among NAFLD subjects without NASH.

\section{Discussion}

In a mixed cohort of patients with NAFLD and controls without fatty liver, we report that subjects with NAFLD had significantly lower RHI values and higher mean arterial stiffness indexes such as Aix and PWV, and that NAFLD subjects also had lower mean MMSE scores in comparison with control subjects without NAFLD.

To the best of our knowledge, no study has yet addressed the relationship between endothelial 
Table 3 Clinical variables of NAFLD patients according to NASH presence

\begin{tabular}{|c|c|c|c|}
\hline Variable & No NASH subjects $(n=28)$ & NASH subjects $(n=52)$ & $p$ \\
\hline Age (years) (mean $\pm S D$ ) & $51.5 \pm 12.8$ & $54.9 \pm 12.8$ & 0.258 \\
\hline Weight (kg) (mean \pm SD) & $78.6 \pm 19.9$ & $79.3 \pm 15.3$ & 0.850 \\
\hline $\mathrm{BMI}\left(\mathrm{kg} / \mathrm{m}^{2}\right)($ mean $\pm \mathrm{SD})$ & $27.6 \pm 6.3$ & $29.3 \pm 5.1$ & 0.812 \\
\hline $\mathrm{SBP}(\mathrm{mm} / \mathrm{Hg})($ mean $\pm \mathrm{SD})$ & $120.1 \pm 13.1$ & $122.5 \pm 14.1$ & 0.443 \\
\hline $\mathrm{DBP}(\mathrm{mm} / \mathrm{Hg})($ mean $\pm \mathrm{SD})$ & $72.3 \pm 9.6$ & $72.9 \pm 9.6$ & 0.771 \\
\hline Gender M/F & $15 / 13$ & $25 / 27$ & 0.815 \\
\hline Hypertension (n/\%) & $8(28.6)$ & $20(38.5)$ & 0.464 \\
\hline Diabetes (n/\%) & $9(32.1)$ & $22(42.3)$ & 0.472 \\
\hline Dyslipidaemia (n/\%) & $4(14.3)$ & $11(21.1)$ & 0.557 \\
\hline Previous cardiovascular diseases & $0(0)$ & $3(5.8)$ & 0.309 \\
\hline Previous cerebrovascular events & 0 & 0 & / \\
\hline RHI (mean \pm SD) & $1.8 \pm 0.51$ & $1.9 \pm 0.52$ & 0.670 \\
\hline Aix (\%) (mean \pm SD) & $\begin{array}{l}141.1 \pm 25.4 \\
26.8 \pm 12.3\end{array}$ & $\begin{array}{l}146.1 \pm 28.1 \\
29.6 \pm 12.2\end{array}$ & $\begin{array}{l}0.338 \\
0.429\end{array}$ \\
\hline PWV (mt/s) (mean \pm SD) & $10.4 \pm 1.9$ & $10.4 \pm 2.2$ & 0.971 \\
\hline MMSE (mean \pm SD) & $27.5 \pm 2.0$ & $27.3 \pm 2.9$ & 0.765 \\
\hline Liver stiffness, kPa & $6.7 \pm 2.7$ & $11.5 \pm 8.0$ & 0.003 \\
\hline \multicolumn{4}{|l|}{ Histology (\%) } \\
\hline \multicolumn{4}{|l|}{ Kleiner steatosis grade $0-3$} \\
\hline $1(n / \%)$ & $16(57.1)$ & $20(38.5)$ & \\
\hline $2(n / \%)$ & $7(25.0)$ & $15(28.8)$ & 0.271 \\
\hline $3(n / \%)$ & $5(17.9)$ & $17(32.7)$ & \\
\hline \multicolumn{4}{|l|}{ Lobular inflammation grade $0-3$} \\
\hline $0(\mathrm{n} / \%)$ & $2(7.1)$ & 0 & \\
\hline $1(\mathrm{n} / \%)$ & $23(82.1)$ & $22(42.3)$ & \\
\hline $2(n / \%)$ & $2(7.1)$ & $29(55.8)$ & $<0.0001$ \\
\hline $3(n / \%)$ & $1(3.6)$ & $1(1.9)$ & \\
\hline \multicolumn{4}{|l|}{ Hepatocellular ballooning (0-2) } \\
\hline $0(n / \%)$ & $11(39.3)$ & $12(23.1)$ & \\
\hline $1(\mathrm{n} / \%)$ & $15(53.6)$ & $20(38.4)$ & 0.010 \\
\hline $2(n / \%)$ & $2(7.1)$ & $20(38.4)$ & \\
\hline \multicolumn{4}{|l|}{ Stage of fibrosis (0-4) } \\
\hline $0(n / \%)$ & $11(39.3)$ & $7(13.5)$ & \\
\hline $1(n / \%)$ & $14(50.0)$ & $11(21.1)$ & \\
\hline $2(n / \%)$ & $3(10.7)$ & $11(21.1)$ & $<0.0001$ \\
\hline $3(n / \%)$ & 0 & $17(32.7)$ & \\
\hline $4(n / \%)$ & 0 & $6(11.5)$ & \\
\hline
\end{tabular}

Significant $\mathrm{p}$ values are indicated in Italics

$S B P$ systolic blood pressure, DBP diastolic blood pressure, $B M I$ body mass index, Aix: augmentation index, $P W V$ pulse wave velocity, $R H I$ reactive hyperemia index, MMSE mini-mental state examination, $\mathrm{kPa}$ kiloPascal

dysfunction markers evaluated by reactive hyperemia peripheral arterial tonometry (RH-PAT) and NAFLD. Some studies analyzed arterial stiffness indexes in subjects with NAFLD [25-27] and just one study evaluated cognitive performance in NAFLD patients [28]. Thus, our findings of impaired vascular damage markers in subjects with NAFLD could appear as novel.

The study by Leite et al. [25] showed that diabetic patients with NAFLD are more likely to have high or increasing aortic stiffness that predicted the development of advanced liver fibrosis transient elastography. The study by Sunbul et al. [27] analyzed patients with biopsyproven NAFLD whereas the study by Seo et al. [28] analyzed subjects with ultrasound defined NAFLD.

In particular the study of Sunbul [27] showed that NAFLD patients compared with controls, had significantly higher PWV and AIx values. Nevertheless, in this previous study authors analyzed the relationship between 
Table 4 Clinical variables of NAFLD patients according to NASH and severity of fibrosis

\begin{tabular}{|c|c|c|c|}
\hline Variable & Subjects with fibrosis $0-1(n=43)$ & Subjects with fibrosis $\geq 2(n=37)$ & $\mathrm{p}$ \\
\hline Age (years) (mean $\pm S D$ ) & $50.2 \pm 11.9$ & $57.8 \pm 12.9$ & 0.008 \\
\hline Weight (kg) (mean \pm SD) & $75.3 \pm 14.0$ & $83.2 \pm 20.4$ & 0.045 \\
\hline $\mathrm{BMI}\left(\mathrm{kg} / \mathrm{m}^{2}\right)($ mean $\pm \mathrm{SD})$ & $27.4 \pm 5.1$ & $30.3 \pm 5.7$ & 0.017 \\
\hline $\mathrm{SBP}(\mathrm{mm} / \mathrm{Hg})($ mean $\pm \mathrm{SD})$ & $117.8 \pm 11.7$ & $126.2 \pm 14.6$ & 0.006 \\
\hline $\mathrm{DBP}(\mathrm{mm} / \mathrm{Hg})($ mean $\pm \mathrm{SD})$ & $71.9 \pm 8.4$ & $73.6 \pm 10.8$ & 0.440 \\
\hline Gender M/F & 24/19 & $16 / 21$ & 0.262 \\
\hline Hypertension (n/\%) & $11(25.6)$ & $17(45.9)$ & 0.057 \\
\hline Diabetes (n/\%) & $10(23.3)$ & $21(56.8)$ & 0.002 \\
\hline dyslipidemia (n/\%) & $7(16.3)$ & $8(21.6)$ & 0.542 \\
\hline Previous cardiovascular diseases & $0(0)$ & $3(8.1)$ & 0.057 \\
\hline Previous cerebrovascular events & 0 & 0 & / \\
\hline $\mathrm{RHI}($ mean $\pm \mathrm{SD})$ & $1.9 \pm 0.54$ & $1.8 \pm 0.47$ & 0.211 \\
\hline Aix (\%) & $139.8 \pm 29.4$ & $149.7 \pm 23.6$ & 0.103 \\
\hline$($ mean $\pm S D)$ & $25.8 \pm 13.2$ & $31.9 \pm 10.4$ & 0.027 \\
\hline PWV (mt/s) (mean \pm SD) & $10.0 \pm 1.9$ & $10.9 \pm 2.3$ & 0.043 \\
\hline MMSE (mean \pm SD) & $27.8 \pm 2.2$ & $26.9 \pm 2.9$ & 0.131 \\
\hline Liver stiffness, kPa & $7.5 \pm 3.6$ & $12.6 \pm 8.9$ & 0.001 \\
\hline \multicolumn{4}{|l|}{ Histology (\%) } \\
\hline \multicolumn{4}{|l|}{ Kleiner steatosis grade 0-3 } \\
\hline $1(n / \%)$ & $29(67.4)$ & $7(18.9)$ & \\
\hline $2(n / \%)$ & $7(16.3)$ & $15(40.5)$ & $<0.0005$ \\
\hline $3(n / \%)$ & $7(16.3)$ & $15(40.5)$ & \\
\hline \multicolumn{4}{|l|}{ Lobular inflammation grade 0-3 } \\
\hline $0(n / \%)$ & $2(4.6)$ & 0 & \\
\hline $1(n / \%)$ & $36(83.7)$ & $9(24.3)$ & \\
\hline $2(n / \%)$ & $4(9.3)$ & $27(73.0)$ & $<0.0005$ \\
\hline $3(n / \%)$ & $1(2.3)$ & $1(2.7)$ & \\
\hline \multicolumn{4}{|l|}{ Hepatocellular ballooning (0-2) } \\
\hline $0(n / \%)$ & $21(48.8)$ & $2(5.4)$ & \\
\hline $1(n / \%)$ & $20(46.5)$ & $15(40.5)$ & $<0.0005$ \\
\hline $2(n / \%)$ & $2(4.6)$ & $20(54.0)$ & \\
\hline
\end{tabular}

Significant $\mathrm{p}$ values are indicated in Italics

$S B P$ systolic blood pressure, $D B P$ diastolic blood pressure, $B M I$ body mass index, Aix augmentation index, $P W V$ pulse wave velocity, $R H I$ reactive hyperemia index, MMSE mini-mental state examination, $\mathrm{kPa}$ kiloPascal

Table 5 Simple linear regression analysis of variables associated with vascular damage indexes (RHI, AIX, PWV and MMSE) in NAFLD subjects with and without NASH

\begin{tabular}{lllll}
\hline Vascular damage indexes & Variable & NASH & No-NASH \\
\cline { 3 - 5 } & & $\mathbf{B}(\mathbf{9 5 \%} \mathbf{C l})$ & - \\
\hline PWV & - & - & 0.008 & - \\
AIX & Kleiner steatosis grade & $4.957(1.385$ to 8.529$)$ & - \\
RHI & - & - & $-1.344(-2.650$ to -0.037$)$ & 0.044 \\
MMSE & Kleiner balloning grade & - & - \\
\hline
\end{tabular}

Adjusted for BMI, dysilipidemia, hypertension, sex, diabetes and age and cardiovascular diseases 
arterial stiffness indexes and only liver fibrosis scores. Thus, our current findings obtained after an analysis of the relationship between arterial stiffness indexes and the full range of hepatic histological changes in NAFLD subjects may be considered a potential original result.

Endothelial dysfunction is one of the earliest events in the pathogenetic process leading to the atherosclerotic disorders [29], and it contributes to the progression of disease through inflammation and thrombosis [30-32].

Studies using the EndoPAT have shown that the RHI score reflects NO-bioavailability [33]. The RHI correlates with the measurement of endothelial vasodilator function in the coronary arteries [34] and with brachial FMD [35]. Patients with a higher degree of cardiovascular involvement exhibit a lower score [36-38]. Notably, RHI values appear to be predictive of cardiovascular outcomes [39-41].

Thus our findings of lower values of RHI in subjects with NAFLD may be suggestive of the raised cardiovascular risk of patients with NAFLD due to a higher prevalence of endothelial dysfunction.

Multivariable analysis of association linking clinical variables and NAFLD showed the significant predictive role of RHI and MMSE. It is possible to speculate that endothelial dysfunction and impaired cognitive performance may represent a potential hallmark of NAFLD and that endothelial function and cognitive markers could be employed as putative indicators of early vascular involvement in this clinical context.

A recent study reported that NAFLD was independently associated with lower cognitive performance independent of CVD and its risk factors [14].

Our finding of lower MMSE values in subjects with NAFLD may be indicative of a lower degree of cognitive performance even in absence of MMSE scores indicating a clinical cognitive dysfunction, in subjects with higher degree of arterial stiffness and lower degree of endothelial mediated vasodilation. Consistent with our findings a recent study [51] showed that a MMSE cut score to 27 resulted in an optimal balance of sensitivity and specificity with an overall correct classification rate of $90 \%$ in a cognitively impaired group (dementia and MCI), thus indicating that a cut-score of 27 might be more appropriate.

Evidence from epidemiology and pathology studies indicates that damage to the vascular system is associated with an increased risk of many types of cognitive impairment [42-44]. Although we have not observed mean MMSE values indicating a cognitive dysfunction in both groups of subjects, our findings of lower MMSE mean scores observed in NAFLD patients (mean MMSE 26.9) and the negative relationship observed between ballooning grade and MMSE may represent a further issue confirming the role of metabolic disturbances linked to NAFLD also in clinical setting of cognitive performance. Nevertheless, we observed no significant association between cognitive performance and histological findings in NAFLD patients without NASH and only a significant negative association between ballooning grade and MMSE in NAFLD subjects with NASH. This finding is novel since that no previous study has not yet reported any relation between histological severity of NAFLD and cognitive performance. Our group recently reported [44] that white matter lesions (WMLs) are not associated with the presence of NAFLD but with its histological severity. This finding may also suggest an alternative pathogenic hypothesis to explain subclinical lower cognitive performance of NAFLD subjects such as small-artery remodeling and direct vascular cognitive impairment (VCI) well expressed by progressive arterial stiffening and endothelial dysfunction [45-50]. These vascular changes are probably related to metabolic disorders underlying NAFLD presence.

Previous studies from our group reported an higher degree of organ damage expressed as the diabetic foot [51], a vascular impairment [52, 53] and the Obstructive Sleep Apnea syndrome (OSAS) [54] in subjects with MS.

Overweight and obesity and associated co-morbidities are established cardiovascular (CV) risk. Endothelial dysfunction (ED) is the initial vascular damage, which precedes fatty streak known to initiate atherosclerosis a progressive disease which often culminates as a sudden cardiovascular event [55].

Arterial stiffness and MS have been reported as associated with cognitive impairment in elderly people. A recent study reported that age (older than 60 years) and MS play a synergistic role in cognitive decline pathogenesis in the elderly population [56].

Obstructive sleep apnea (OSA) and type 2 diabetes (T2D) are also associated with endothelial dysfunction [57], whereas increasing age, liver fat, and triglyceride are all related to increased aortic stiffness in adults [58] and a recent study indicates that NAFLD and MS have a synergistic impact on the subclinical atherosclerosis $[59,60]$.

Furthermore, a recent study reported that nonalcoholic fatty liver disease is associated with a smaller total cerebral brain volume, indicating a possible link between hepatic steatosis and brain aging [61].

These factors may represent possible explanation of our findings of a higher degree of vascular impairment in subjects with NAFLD.

Our findings consistent with previous study [62] underlined that the reported higher degree of arterial stiffness in NAFLD patients compared with controls might be related to the higher prevalence of cardiometabolic risk factors in NAFLD patients. 
Thus, in NAFLD clinical setting liver and vessels represent parallel end-organ damage target of MS and insulin resistance.

This issue is furtherly confirmed by our findings about differences among NAFLD subjects in relation to NASH presence and fibrosis severity that showed no difference with regard of RHI and arterial stiffness markers in the two groups of subjects (NASH vs non NASH).

This is an interesting finding probably due to the fact the NAFLD subjects with NASH and those without $\mathrm{NASH}$ and subjects categorized in relation of fibrosis severity show similar prevalence of cardiovascular risk factors such as hypertension and diabetes and they also show not significant difference with regard of the mean value of arterial blood pressure and plasma cholesterol levels.

Nevertheless, although the presence of NASH does not seem significantly associated to a higher degree of vascular damage in patients with NAFLD our findings report a peculiar relationship between some histologic hepatic findings and vascular damage markers only in NASH subjects. Simple logistic regression analysis showed a negative association between ballooning grade and MMSE in NASH patients and a positive association has been observed in NASH subjects between steatosis grade and augmentation index.

Arterial stiffness is due to a complex interplay between dynamic or constant forces and structural and cellular components of the vascular wall such as hormones, salt and glucose aging and blood pressure [63, 64]. Resiliency and compliancy of the vascular wall depend on two proteins: collagen and elastin. The presence of such molecules in arterial wall is maintained by a constant interplay of production and degradation. An inflammatory milieu can trigger an impairment of this balance, driving to overproduction of altered collagen and impaired presence of elastin, leading to increased arterial stiffness [56]. Arterial hypertension and diabetes mellitus and ageing represent the main causes of these vascular alterations that worsen artery stiffening.

We observed no difference in main cardiovascular risk factor between NAFLD subjects with NASH and those without NASH, thus our findings of a significant relation between two histologic hepatic markers such as ballooning and steatosis grade could underline a possible prevalent role of a inflammatory milieu in arterial stiffening and cerebral microvascular disease pathogenesis. Many studies evaluated if NAFLD contributed to other outcomes, such as cardiovascular mortality; and most of them demonstrated an association, but no causality could be shown [65-67]. In this light liver disease and atherogenesis might be mediated by inflamed visceral adipose tissue: In this pathogenetic scenario, nonalcoholic steatohepatitis and mainly NASH presence might be related to the presence of vascular disease in two ways: first, through the production of some inflammatory, prothrombotic and oxidative-stress mediators and, second, by means the direct involvement of nonalcoholic fatty liver disease in insulin resistance mechanism and atherogenic dyslipidemia.

\section{Limitations}

The main limitation of this study lies in its cross-sectional nature, unable to identify pathogenic mechanisms linking vascular damage and liver fibrosis. A further methodological question is the potentially limited external validity of the results for different populations and settings. Our study included a cohort of Italian NAFLD patients, largely obese, at high prevalence of NASH and severe fibrosis, who may be different, in terms of both metabolic features and severity of liver disease, from the majority of prevalent cases of NAFLD in the general population. The lack of data on a control Sicilian population might further limit the strength of our results; however higher prevalence of vascular damage in subjects with NAFLD seem to be a finding potentially applicable to other italian cohorts.

Another limitation is that our study included a cohort of Italian NAFLD patients referred to a tertiary referral center, largely obese, with abnormal ALT levels, and at high prevalence of NASH and severe fibrosis, who may be different, in terms of metabolic features, ALT levels and severity of liver disease, from the majority of prevalent cases of NAFLD in the general population".

Finally, we also need data on serum levels and liver expression of proinflammatory and profibrogenic cytokines potentially involved in vascular changes of NAFLD patients.

\section{Conclusions}

This study reports that NAFLD subjects in comparison to controls without NAFLD had: (1) lower mean values of RHI; (2) higher mean values of PWV and Aix; (3) lower MMSE; (4) a significant relationship at multivariate analysis between RHI and MMSE with NAFLD, (5) a significant negative relationship between ballooning grade and MMSE grade only in NASH subjects; (6) a significant positive relationship between steatosis and augmentation index only in NASH subjects.

Several previous studies [54-56] pinpointed the inflammatory background of nonalcoholic fatty liver disease, thus future studies will be addressed to evaluate the relationship between inflammatory markers and arterial stiffness and endothelial function indexes in NAFLD subjects.

Future research could address these issues both by means of longitudinal studies to evaluate incidence of 
new-onset cardiovascular events and their connection with arterial stiffness, endothelial and cognitive markers. They also should analyze the beneficial effects of cardiovascular drugs such as statins and ACE inhibitors on these surrogate markers (indicators of arterial stiffness, endothelial function and cognitive performance) in NAFLD subjects.

\section{Authors' contributions}

AT: designed the research study and wrote the paper, collected and analysed the data. SP: designed the research study, performed the research, collected and analysed the data. AC, CM, VDC, DDR, MD, RF, RZ, DC, CC, VDM, AL, FM, GM, GM: performed the research. AC: performed the research, designed the research study. AP: designed the research study. All authors read and approved the final manuscript.

\section{Author details}

${ }^{1}$ U.O.C di Medicina Interna con Stroke Care, Dipartimento Biomedico di Medicina Interna e Specialistica (Di.Bi.M.I.S), University of Palermo, P.zza delle Cliniche n.2, Palermo 90127, Italy. ${ }^{2}$ Sezione di Gastroenterologia e Epatologia, Dipartimento Biomedico di Medicina Interna e Specialistica (Di.Bi.M.I.S), University of Palermo, Palermo, Italy. ${ }^{3}$ Dipartimento di Scienze per la Promozione della Salute e Materno Infantile, University of Palermo, Palermo, Italy. ${ }^{4}$ Medicina Generale Palermo, Palermo, Italy. ${ }^{5}$ Cattedra di Anatomia Patologica, University of Palermo, Palermo, Italy. ${ }^{6}$ Dipartimento di Scienze Mediche e Chirurgiche, "Alma Mater Studiorum", University of Bologna, Bologna, Italy.

\section{Acknowledgements}

Authors have no acknowledgement to do.

\section{Competing interests}

The authors declare that they have no competing interests.

\section{Availability of data and materials}

All data and material are available on figashare.

\section{Consent for publication}

All enrolled patients released a consent to publish from the participant (or legal parent or guardian for children) to report individual patient data.

\section{Ethics approval and consent to participate}

This protocol study was approved by the Ethics Committee of the Policlinico P. Giaccone Hospital and all patients gave their written informed consent to participate in the study, as well as for sampling and banking of the biological material. The study protocol conforms to the ethical guidelines of the 1975 Declaration of Helsinki and written informed consent was obtained from all patients. A statement of ethics approval with the name of the ethics committee's and the reference number if appropriate.

\section{Funding}

This study was funded by Grant from PRIN 2010-2011 (Prot. N. 2010C4JJWB).

\section{Publisher's Note}

Springer Nature remains neutral with regard to jurisdictional claims in published maps and institutional affiliations.

Received: 29 November 2017 Accepted: 1 February 2018 Published online: 16 February 2018

\section{References}

1. Fracanzani AL, Tiraboschi S, Pisano G, Consonni D, Baragetti A, Bertelli C, Norata D, Valenti L, Grigore L, Porzio M, Catapano A, Fargion S. Progression of carotid vascular damage and cardiovascular events in nonalcoholic fatty liver disease patients compared to the general population during 10 years of follow-up. Atherosclerosis. 2016;246:208-13.
2. Lonardo A, Sookoian S, Pirola CJ, Targher G. Non-alcoholic fatty liver disease and risk of cardiovascular disease. Metabolism. 2015;65(8):1136-50 (Epub ahead of print)

3. Lonardo A, Sookoian S, Chonchol M, Loria P, Targher G. Cardiovascular and systemic risk in nonalcoholic fatty liver disease-atherosclerosis as a major player in the natural course of NAFLD. Curr Pharm Des. 2013;19(29):5177-92.

4. Miele L, Targher G. Understanding the association between developing a fatty liver and subsequent cardio-metabolic complications. Expert Rev Gastroenterol Hepatol. 2015;9(10):1243-5.

5. Targher G, Marra F, Marchesini G. Increased risk of cardiovascular disease in non-alcoholic fatty liver disease: causal effect or epiphenomenon? Diabetologia. 2008:51(11):1947-53.

6. Widlansky ME, Gokce N, Keaney JF Jr, Vita JA. The clinical implications of endothelial dysfunction. J Am Coll Cardiol. 2003;42:1149-60.

7. Hijmering ML, Stroes ES, Pasterkamp G, Sierevogel M, Banga JD, Rabelink TJ. Variability of flow mediated dilation: consequences for clinical application. Atherosclerosis. 2001;157:369-73.

8. Kuvin JT, Patel AR, Sliney KA, et al. Assessment of peripheral vascular endothelial function with finger arterial pulse wave amplitude. Am Heart J. 2003;146:168-74.

9. Hamburg NM, Keyes MJ, Larson MG, et al. Cross-sectional relations of digital vascular function to cardiovascular risk factors in the Framingham Heart Study. Circulation. 2008;117:2467-74.

10. Meyer ML, Tanaka H, Palta P, Cheng S, Gouskova N, Aguilar D, Heiss G. Correlates of segmental pulse wave velocity in older adults: the atherosclerosis risk in communities (ARIC) study. Am J Hypertens. 2016;29(1):114-22.

11. Lenders M, Hofschröer V, Schmitz B, Kasprzak B, Rohlmann A, Missler M, Pavenstädt H, Oberleithner H, Brand SM, Kusche-Vihrog K, Brand E. Differential response to endothelial epithelial sodium channel inhibition ex vivo correlates with arterial stiffness in humans. J Hypertens. 2015;33(12):2455-62.

12. Vlachopoulos C, Manesis E, Baou K, Papatheodoridis G, Koskinas J, Tiniakos D, Aznaouridis K, Archimandritis A, Stefanadis C. Increased arterial stiffness and impaired endothelial function in nonalcoholic Fatty liver disease: a pilot study. Am J Hypertens. 2010;23(11):1183-9.

13. Salvi P, Ruffini R, Agnoletti D, Magnani E, Pagliarani G, Comandini G, Praticò A, Borghi C, Benetos A, Pazzi P. Increased arterial stiffness in nonalcoholic fatty liver disease: the Cardio-GOOSE study. J Hypertens. 2010;28(8):1699-770.

14. Seo SW, Gottesman RF, Clark JM, Hernaez R, Chang Y, Kim C, Ha KH, Guallar E, Lazo M. Nonalcoholic fatty liver disease is associated with cognitive function in adults. Neurology. 2016;86(12):1136-42.

15. Villanova N, Moscatiello S, Ramilli S, Bugianesi E, Magalotti D, Vanni E, Zoli M, Marchesini G. Endothelial dysfunction and cardiovascular risk profile in nonalcoholic fatty liver disease. Hepatology. 2005:42(2):473-80.

16. ESH/ESC Guidelines for the management of arterial hypertension. The Task Force for the management of arterial hypertension of the European Society of Hypertension (ESH) and of the European Society of Cardiology (ESC). J Hypertens. 2013;31:1281-357.

17. Standards of Medical Care in. Diabetes-2014. Diabetes Care. 2014;37(Supplement 1):S14-80.

18. Jellinger PS, Smith DA, Mehta AE, Ganda O, Handelsman Y, Rodbard HW et al. American association of clinical endocrinologists' guidelines for management of Dyslipidemia and prevention of atherosclerosis. Endocr Pract. 2012;18(Suppl 1):1-78.

19. Taylor KJ, Riely CA, Hammers L, et al. Quantitative US attenuation in normal liver and in patients with diffuse liver disease: importance of fat. Radiology. 1986;160:65-71.

20. Boursier J, Zarski JP, de Ledinghen $V$, et al. Multicentric Group from ANRS/HC/EP23 FIBROSTAR Studies. Determination of reliability criteria for liver stiffness evaluation by transient elastography. Hepatology. 2013;57:1182-91.

21. Colloredo G, Guido M, Sonzogni A, et al. Impact of liver biopsy size on histological evaluation of chronic viral hepatitis: the smaller the sample, the milder the disease. J Hepatol. 2003;39:239-44.

22. Kleiner DE, Brunt EM, Van Natta M, et al. Design and validation of a histological scoring system for nonalcoholic fatty liver disease. Hepatology. 2005:411:313-21.

23. Fracanzani AL, Burdick L, Raselli S, et al. Carotid artery intima-media thickness in non alcoholic fatty liver disease. Am J Med. 2008;121:72-8. 
24. Folstein MF, Folstein SE, McHugh PR. Mini-mental state: a practical method for grading the state of patients for the clinician. J Psychiatric Res. 1975;12:189.

25. Leite NC, Villela-Nogueira CA, Fereira MT, Cardoso CR, Salles GF. Increasing aortic stiffness is predictive of advanced liver fibrosis in patients with type 2 diabetes: the Rio-T2DM cohort study. Liver Int. 2015. https://doi. org/10.1111/liv.12994

26. Fargion S, Porzio M, Fracanzani AL. Nonalcoholic fatty liver disease and vascular disease: state-of-the-art. World J Gastroenterol. 2014;20(37):13306-24.

27. Sunbul M, Agirbasli M, Durmus E, Kivrak T, Akin H, Aydin Y, Ergelen R, Yilmaz Y. Arterial stiffness in patients with non-alcoholic fatty liver disease is related to fibrosis stage and epicardial adipose tissue thickness. Atherosclerosis. 2014;237(2):490.

28. Seo SW, Gottesman RF, Clark JM, Hernaez R, Chang Y, Kim C, Ha KH, Guallar E, Lazo M. Nonalcoholic fatty liver disease is associated with cognitive function in adults. Neurology. 2016;86(12):1136-42.

29. Davies PF. Endothelial mechanisms of flow-mediated athero-protection and susceptibility. Circ Res. 2007;101(1):10-2

30. Libby P, Ridker PM, Hansson GK, et al. Inflammation in atherosclerosis: from pathophysiology to practice. J Am Coll Cardiol. 2009;54(23):2129-38.

31. Lamon BD, Hajjar DP. Inflammation at the molecular interface of atherogenesis: an anthropological journey. Am J Pathol. 2008;173(5):1253-64.

32. Napoli C, Ignarro LJ. Nitric oxide and pathogenic mechanisms involved in the development of vascular diseases. Arch Pharm Res. 2009;32(8):1103-8.

33. Nohira A, Gerhard-Herman M, Creager MA, Hurley S, Mitra D, Ganz P. Role of nitric oxide in regulation of digital pulse volume amplitude in humans. J Appl Physiol. 2006;101(2):545-8.

34. Bonetti PO, Pumper GM, Higano ST, Holmes DR, Kuvin JT, Lerman A. Noninvasive identification of patients with early coronary atherosclerosis by assessment of digital reactive hyperemia. J Am Coll Cardiol. 2004:44(11):2137-41.

35. Kuvin JT, Patel RP, Sliney KA, Pandian NG, Sheffy J, Schnall RP, Karas RH, Udelson JE. Assessment of peripheral vascular endothelial function with finger arterial pulse wave amplitude. Am Heart J. 2003;146(1):168-74.

36. Bonetti PO. Attenuation of digital reactive hyperemia in patients with early and advanced coronary artery disease. J Am Coll Cardiol. 2005;45(3):407A.

37. Hirata Y, Nagata D, Suzuki E, Nishimatsu H, Suzuki J, Nagai R. Diagnosis and treatment of endothelial dysfunction in cardiovascular disease. Int Heart J. 2010;51(1):1-6.

38. Hamburg NM, Keyes MJ, Larson MG, Vasan RS, Schnabel R, Pryde MM, Mitchell GF, Sheffy J, Vita JA, Benjamin EJ. Cross-sectional relations of digital vascular function to cardiovascular risk factors in the Framingham heart study. Circulation. 2008;117(19):2467-74.

39. Rubinshtein R, Kuvin JT, Soffler M, Lennon RJ, Lavi S, Nelson RE, Pumper GM, Lerman LO, Lerman A. Assessment of endothelial function by non-invasive peripheral arterial tonometry predicts late cardiovascular adverse events. Eur Heart J. 2010;31(9):1142-8.

40. Yamaoka-Tojo M, Tojo T, Kosugi R, Hatakeyama Y, Yoshida Y, Machida Y, Aoyama N, Masuda T, Izumi T. Effects of ezetimibe add on therapy for high-risk patients with dyslipidemia. Lipids Health Dis. 2009;8(1):41.

41. Corey KE, Kartoun U, Zheng H, Chung RT, Shaw SY. Using an electronic medical records database to identify non-traditional cardiovascular risk factors in nonalcoholic fatty liver disease. Am J Gastroenterol. 2016;111(5):671 (Epub ahead of print)

42. Corriveau RA, Bosetti F, Emr M, Gladman JT, Koenig Jl, Moy CS, Pahigiannis K, Waddy SP, Koroshetz W. The science of vascular contributions to cognitive impairment and dementia (VCID): a framework for advancing research priorities in the cerebrovascular biology of cognitive decline. Cell Mol Neurobiol. 2016:36(2):281-8.

43. Gooch J, Wilcock DM. Animal models of vascular cognitive impairment and dementia (VCID). Cell Mol Neurobiol. 2016;36(2):233-9.

44. Reitz C, Luchsinger JA, Mayeux R. Vascular disease and cognitive impairment. Expert Rev Neurother. 2008;8(8):1171-4.

45. Fernando MS, Ince PG, MRC Cognitive Function and Ageing Neuropathology Study Group. Vascular pathologies and cognition in a population-based cohort of elderly people. J Neurol Sci. 2004;226:13-7.

46. Fernando MS, Simpson JE, Matthews F, Brayne C, Lewis CE, Barber R, Kalaria RN, Forster G, Esteves F, Wharton SB, Shaw PJ, O'Brien JT, Ince
PG, MRC Cognitive Function and Ageing Neuropathology Study Group. White matter lesions in an unselected cohort of the elderly: molecular pathology suggests origin from chronic hypoperfusion injury. Stroke. 2006:37:1391-8.

47. Reed BR, Mungas DM, Kramer JH, Ellis W, Vinters HV, Zarow C, Jagust WJ Chui HC. Profiles of neuropsychological impairment in autopsy-defined Alzheimer's disease and cerebrovascular disease. Brain. 2007;130:731-9.

48. Gainotti G, Ferraccioli M, Vita MG, Marra C. Patterns of neuropsychological impairment in $\mathrm{MCl}$ patients with small subcortical infarcts or hippocampal atrophy. J Int Neuropsychol Soc. 2008;14:611-9.

49. Tomlinson BE, Blessed G, Roth M. Observations on the brains of demented old people. J Neurol Sci. 1970;11:205-42.

50. Kalaria RN, Kenny RA, Ballard CG, Perry R, Ince P, Polvikoski T. Towards defining the neuropathological substrates of vascular dementia. J Neurol Sci. 2004;226:75-80.

51. Tuttolomondo A, Casuccio A, Guercio G, Maida C, Del Cuore A, Di Raimondo D, Simonetta I, Di Bona D, Pecoraro R, Della Corte V, Gulotta E, Gulotta G, Pinto A. Arterial stiffness, endothelial and cognitive function in subjects with type 2 diabetes in accordance with absence or presence of diabetic foot syndrome. Cardiovasc Diabetol. 2017;16(1):2.

52. Petta S, Tuttolomondo A, Gagliardo C, Zafonte R, Brancatelli G, Cabibi D, Cammà C, Di Marco V, Galvano L, La Tona G, Licata A, Magliozzo F, Maida C, Marchesini G, Merlino G, Midiri M, Parrinello G, Torres D, Pinto A, Craxi A. The presence of white matter lesions is associated with the fibrosis severity of nonalcoholic fatty liver disease. Medicine (Baltimore). 2016;95(16):e3446.

53. Tuttolomondo A, Pecoraro R, Di Raimondo D, Di Sciacca R, Canino B, Arnao V, Buttà C, Della Corte V, Maida C, Licata G. Pinto A Immuneinflammatory markers and arterial stiffness indexes in subjects with acute ischemic stroke with and without metabolic syndrome. Diabetol Metab Syndr. 2014;61:28

54. Petta S, Marrone O, Torres D, Buttacavoli M, Cammà C, Di Marco V, Licata A, Lo Bue A, Parrinello G, Pinto A, Salvaggio A, Tuttolomondo A, Craxi A, Bonsignore MR. Obstructive sleep apnea is associated with liver damage and atherosclerosis in patients with non-alcoholic fatty liver disease. PLoS ONE. 2015;10(12):e0142210.

55. Gupta AK, Ravussin E, Johannsen DL, Stull AJ, Cefalu WT, Johnson WD. Endothelial dysfunction: an early cardiovascular risk marker in asymptomatic obese individuals with prediabetes. Br J Med Med Res. 2012;2(3):413-23.

56. Kim YS, Kim DH, Choi BH, Sohn EH, Lee Ay. Relationship between brachial-ankle pulse wave velocity and cognitive function in an elderly community-dwelling population with metabolic syndrome. Arch Gerontol Geriatr. 2009:49(1):176-9.

57. Bironneau V, Goupil F, Ducluzeau PH, Le Vaillant M, Abraham P, Henni S, Dubois S, Paris A, Priou P, Meslier N, Sanguin C, Trzépizur W, Andriantsitohaina R, Martinez MC, Gagnadoux F. Association between obstructive sleep apnea severity and endothelial dysfunction in patients with type 2 diabetes. Cardiovasc Diabetol. 2017;16(1):39.

58. Rider OJ, Banerjee R, Rayner JJ, Shah R, Murthy VL, Robson MD, Neubauer S. Investigating a liver fat: arterial stiffening pathway in adult and childhood obesity. Arterioscler Thromb Vasc Biol. 2016;36(1):198-203.

59. Hong HC, Hwang SY, Ryu JY, Yoo HJ, Seo JA, Kim SG, Kim NH, Baik SH, Cho DS, Choi KM. The synergistic impact of nonalcoholic fatty liver disease and metabolic syndrome on subclinical atherosclerosis. Clin Endocrinol (Oxf). 2015. https://doi.org/10.1111/cen.12940.

60. Gomez-Sanchez L, Garcia-Ortiz L, Patino-Alonso MC, Recio-Rodriguez J, Fernando R, Marti R, Agudo-Conde C, Rodriguez-Sanchez E, MaderueloFernandez JA, Ramos R, Gomez-Marcos MA. MARK Group Association of metabolic syndrome and its components with arterial stiffness in Caucasian subjects of the MARK study: a cross-sectional trial. Cardiovasc Diabetol. 2016;15(1):148.

61. Weinstein G, Zelber-Sagi S, Preis SR, Beiser AS, DeCarli C, Speliotes EK, Satizabal CL, Vasan RS, Seshadri S. Association of nonalcoholic fatty liver disease with lower brain volume in healthy middle-aged adults in the Framingham study. JAMA Neurol. 2018;75(1):97-104.

62. Jaruvongvanich V, Chenbhanich J, Sanguankeo A, Rattanawong P, Wijarnpreecha K, Upala S. Increased arterial stiffness in nonalcoholic fatty liver disease: a systematic review and meta-analysis. Eur J Gastroenterol Hepatol. 2017;29(9):e28-35. 
63. O'Bryant SE, Humphreys JD, Smith GE, Ivnik RJ, Graff-Radford NR, Petersen $\mathrm{RC}$, Lucas JA. Detecting dementia with the mini-mental state examination in highly educated individuals. Arch Neurol. 2008;65(7):963-7.

64. Haukeland JW, Dama JK, Konopski Z, Løberg EM, Haaland T, Goverud I, et al. Systemic inflammation in nonalcoholic fatty liver disease is characterized by elevated levels of CCL2. J Hepatol. 2006:44:1167-74.

65. Johnson CP, Baugh R, Wilson CA, Burns J. Age related changes in the tunica media of the vertebral artery: implications for the assessment of vessels injured by trauma. J Clin Pathol. 2001;54:139-45.
66. Kugelmas M, Hill DB, Vivian B, Marsano L, McClain CJ. Cytokines and NASH: a pilot study of the effects of lifestyle modification and vitamin $E$. Hepatology. 2003;38:41

67. Targher G, Day CP, Bonora E. Risk of cardiovascular disease in patients with nonalcoholic fatty liver disease. NEJM. 2010;363:1341-50.

\section{Submit your next manuscript to BioMed Central and we will help you at every step:}

- We accept pre-submission inquiries

- Our selector tool helps you to find the most relevant journal

- We provide round the clock customer support

- Convenient online submission

- Thorough peer review

- Inclusion in PubMed and all major indexing services

- Maximum visibility for your research

Submit your manuscript at

www.biomedcentral com/submit 